\title{
Blood pressure and its circadian pattern in obese and lean premenopausal women
}

\author{
José Silva-Nunes ${ }^{1-3}$, Miguel Brito ${ }^{1}$, Luisa Veiga ${ }^{1}$ \\ ${ }^{1} H \& T R C$ - ESTeSL/IPL, Lisbon, Portugal \\ ${ }^{2}$ Curry Cabral Hospital, CHULC, Lisbon, Portugal \\ ${ }^{3}$ NOVA Medical School, New University of Lisbon, Lisbon, Portugal
}

\begin{abstract}
Background. Obesity is frequently referred to as an independent risk factor for high blood pressure and hypertension is very prevalent among obese people. The aims of this study were: to compare office-based and $24 \mathrm{~h}$ blood pressure $(\mathrm{BP})$ and its circadian pattern between lean and obese women; to study correlations between $\mathrm{BP}$, insulin resistance (IR) and markers of subclinical inflammation/early atherosclerosis.

Material and methods. Eighty-eight lean and 107 otherwise healthy obese women were characterized for anthropometrics, BP (office-based determinations and $24 \mathrm{~h} \mathrm{ABPM}$ ) and for glucose, insulin, triglycerides, inteleukin 6 (IL-6), tumor necrosis factor alpha (TNF- $\alpha$ ), high-sensitivity $\mathrm{C}$ reactive protein (hs-CRP), retinol-binding protein 4 (RBP-4), leptin, adiponectin, resistin, monocyte chemoattractant protein 1 (MCP-1), intercellular adhesion molecule 1 (ICAM-1), and vascular-cellular adhesion molecule 1 (VCAM-1). Insulin resistance was determined by homeostasis model assessment of insulin resistance (HOMA-IR), quantitative insulin sensitivity check index (QUICKI), and McAuley indexes (also Matsuda in obese).

Results. Obese group presented higher office-based systolic/diastolic BP, systolic ambulatory blood pressure monitoring $(\mathrm{ABPM})$, and more non-dippers. HOMA-IR and body fat was correlated to systolic $(\mathrm{r} 2=0.176)$ and glucose to diastolic ( $\mathrm{p}=0.008 ; \mathrm{r}=0.256)$ ABPM. Age, QUICKI, and TNF- $\alpha$ was correlated with dipping $(\mathrm{r} 2=0.172)$; adiponectin, age, BMI, and glucose to systolic $(\mathrm{r} 2=0.226)$ and diastolic $(\mathrm{r} 2=0.215)$ office-based BP. Concerning lean women, MCP-1 was associated with diastolic ABPM ( $p=0.013 ; \mathrm{r}=0.267)$. Systolic office-based BP was associated with waist-to-hip ratio $(\mathrm{p}=0.01 ; \mathrm{r}=0.273)$; this and RBP- 4 was correlated with office-based diastolic BP $(r 2=0.12)$. Conclusion. Although relatively healthy, obese women present higher BP than lean. Anthropometrics, IR, and fasting glucose all influence BP in obesity; additionally, IR is involved in non-dipping. No strong correlation exists between $\mathrm{BP} /$ dipping and subclinical inflammation in either group of women.
\end{abstract}

Key words: obesity; hypertension; cardiovascular diseases; dipping; subclinical inflammation

Arterial Hypertens. 2020, vol. 24, no. 1, pages: 30-37

DOI: 10.5603/AH.a2020.0005

Address for correspondence: Prof. Luisa Carvalho Veiga

H\&TRC — ESTeSL/IPL, Av. João II lote 4.69.01, 1990-096 Lisbon, Portugal; e-mail: luisa.veiga@estesl.ipl.pt

V M Copyright $\odot 2020$ Via Medica, ISSN 2449-6170 


\section{Introduction}

Obesity is frequently referred to as an independent risk factor for high blood pressure and hypertension is very prevalent among obese people [1]. Compared to lean individuals, the National Health and Nutrition Examination Survey III Study showed that the odds ratio for the presence of hypertension was 1.7 for overweight, 2.6 for class I obesity, 3.7 for class II obesity and 4.8 for class III obesity [2]. Being both obesity and hypertension independent cardiovascular risk factors, obese hypertensive patients represent very high-risk individuals [3]. In the presence of excessive fat mass, the dysfunctional adipose tissue produces higher levels of adipokines that may interfere at several steps of blood pressure control [4-7]. On the other hand adiponectin, an adipokine with reported beneficial effects on blood pressure lowering, is synthesized at lower levels [8-10]. Moreover, obesity is associated with a hyperactivation of the sympathetic nervous system, which contributes both to an increase in blood pressure and to the blockade of the normal nocturnal fall in blood pressure [5, 11-13]. The aim of this study was to compare classic office-based and $24 \mathrm{~h}$ mean blood pressure and its circadian pattern between obese otherwise healthy and lean women without known history of hypertension. Secondarily, we aimed to study correlations of blood pressure, determined by the two methods, with insulin resistance, markers of subclinical inflammation and early atherosclerosis in each group of women.

\section{Material and methods}

\section{Subjects}

The obese group consisted in 107 obese Caucasian premenopausal women who attended the obesity outpatient clinic at the Curry Cabral Hospital - C.H.L.C. (Lisbon, Portugal). Their age ranged from 18 to 50 years old and their body mass index (BMI) was $\geq 30 \mathrm{~kg} / \mathrm{m}^{2}$. All of them referred less than $10 \%$ variation on their body weight in the previous year.

The control group consisted in 88 healthy Caucasian premenopausal women, who either attended to a routine health check or belonged to the health care staff of Curry Cabral Hospital - C.H.L.C. They were aged from 18 to 50 years old, body mass index (BMI) from 18,5 to $24,9 \mathrm{~kg} / \mathrm{m}^{2}$, and referring less than $10 \%$ variation on their body weight in the previous year.

No woman was pregnant or had been pregnant in the precedent 12 months. We considered only women without previous diagnosis of any acute/chron- ic health conditions (except obesity for the obese group), namely previous diagnosis of hypertension. No woman was on any pharmacological regimen (except for oral contraceptives) or took any sporadic drug in the previous 7 days.

The study was conducted following the approval of the institutional scientific and ethical boards accordingly to the standards of the Declaration of Helsinki. Additionally, an informed consent was signed by all participants.

\section{Clinical evaluation}

Each woman was characterized for total body weight, BMI, waist and hip circumferences, and waist-to-hip ratio. The total body fat mass (absolute and percentage of body weight) was assessed by bioelectrical impedance (Tanita TBF-300A', Tanita Europe B.V., Hoofddorp, The Netherlands).

Office-based blood pressure was assessed by the mean value of 2 determinations at the left arm, in the standard recommended conditions with a 5 minutes interval, using an electronic device with appropriated sized cuffs (CASMED 740 monitor, CAS Medical Systems Inc, Branford, CT, USA). Women were classified as hypertensive if the mean values were $\geq 140$ $\mathrm{mm} \mathrm{Hg}$ for systolic or $\geq 90 \mathrm{~mm} \mathrm{Hg}$ for diastolic blood pressure.

ABPM was performed during a $24 \mathrm{~h}$ period, in a regular day, with registrations every $30 \mathrm{~min}-$ utes during daytime (from 07:00 am to 11:00 pm) and every hour for the night-time (from 11:00 pm to $07: 00 \mathrm{am}$ ) with a portable electronic device (SpaceLabs $90207^{\circ}$ monitor, SpaceLabs Healthcare, Issaquah, WA, USA) and appropriated sized cuffs. The device established the mean values of systolic and diastolic blood pressure for daytime, night-time and the overall $24 \mathrm{~h}$ period. Women were classified as hypertensive if mean values were $\geq 130 / 80 \mathrm{~mm} \mathrm{Hg}$ for the overall $24 \mathrm{~h}, \geq 135 / 85 \mathrm{~mm} \mathrm{Hg}$ for the daytime or $\geq 120 / 70 \mathrm{~mm} \mathrm{Hg}$ for the night-time periods accordingly to the European Society of Hypertension and European Society of Cardiology criteria [11]. They were considered as dippers if $\mathrm{a} \geq 10 \%$ decrease in mean night-time blood pressure occurred compared to mean daytime blood pressure.

Women answered a small questionnaire regarding smoking status, use of oral contraceptives and the existence of diagnosed hypertension among first degree relatives.

\section{Blood sample collection and measurements} After a period of $10 \mathrm{~h}$ fasting, a venous blood sample was collected from obese and lean women for assessment of glucose, insulin, triglycerides, interleu- 
kin 6 (IL-6), tumor necrosis factor alpha (TNF- $\alpha$ ), high-sensitivity C-reactive protein (hs-CRP), retinol-binding protein 4 (RBP-4), leptin, adiponectin, resistin, monocyte chemoattractant protein 1 (MCP-1), intercellular adhesion molecule 1 (ICAM-1), and vascular-cellular adhesion molecule 1 (VCAM-1). Additionally, a classic $75 \mathrm{~g}$ oral glucose tolerance test was performed with blood samples collected after 30, 60, 90, and 120 minutes for the assessment of glucose and insulin. Serum samples were obtained by low-speed centrifugation, stored at a $-80^{\circ} \mathrm{C}$ ultra-freezer, and thawed just before each assay.

Glucose and triglycerides were determined by automated chemistry analyzer (Vitros ${ }^{\oplus}$ 5,1 FS Chemistry System, Ortho-Clinical Diagnosis Inc, Rochester, NY, USA) and hs-CRP concentration by a nephelometer system using CardioPhase hsCRP assay (Siemens Healthcare Diagnostics Inc, Tarrytown, NY, USA). Leptinemia was assessed by radioimmunoassay technique (EMD Millipore Corporation, Billerica, MA, USA). Insulinemia was determined by a chemiluminescent immunometric technique (IMMULITE 2000 Immu- $^{\bullet}$ noassay System, Siemens Healthcare Diagnostics Inc, Tarrytown, NY, USA). Serum IL-6, TNF- $\alpha$, RBP-4, adiponectin, resistin, MCP-1, ICAM-1, and VCAM-1 concentrations were all measured by enzyme-linked immunosorbent assay following the manufacturer's instructions (R\&D Systems Inc., Minneapolis, MN, USA). Insulin resistance/sensitivity was assessed by the application of four mathematical equations as follows:

- homeostasis model assessment of insulin resistance (HOMA-IR) using the formula: fasting insulin in $\mu \mathrm{U} / \mathrm{mL} \times$ fasting glucose in $\mathrm{mg} / \mathrm{dL} / 405$;
- quantitative insulin sensitivity check index (QUICKI): $1 /[\log$ (fasting insulin in $\mu \mathrm{U} / \mathrm{mL})+\log ($ fasting glucose in $\mathrm{mg} / \mathrm{dL})]$;

- McAuley index (for assessment of insulin sensitivity): $\exp [2.63-0.28 \times \log$ (fasting insulin in $\mu \mathrm{U} / \mathrm{mL}-0.31 \times \log ($ fasting triglycerides in $\mathrm{mg} / \mathrm{dl} / 87.72]$;

- Matsuda formula (also an index of insulin sensitivity): $10.000 / \mathrm{SqRt}$ [fasting insulin in $\mu \mathrm{U} / \mathrm{mL} \times$ fasting glucose in $\mathrm{mg} / \mathrm{dL} \times$ mean (insulin at 0,30 , 60,90 , and $120 \mathrm{~min}$ in $\mu \mathrm{U} / \mathrm{mL}$ ) $\times$ mean (glucose at $0,30,60,90$, and $120 \mathrm{~min}$ in $\mathrm{mg} / \mathrm{dL}$.

\section{Statistical analysis}

Data are reported as mean \pm SD. Comparisons between groups were made by t-Student test. The interactions between non-continuous parameters were analyzed by $\chi^{2}$ test.

Simple associations were tested by Spearman $r$ test and multiple regression analysis was carried out by the use of a forward stepwise model. A p value $<0.05$ was considered statistically significant. All determinations were performed using SPSS software, version 18.0 (IBM Corporation, Armonk, NY, USA).

\section{Results}

The characterization of obese and lean groups is depicted in Table 1. In the obese group, office-based systolic blood pressure was significantly correlated to systolic blood pressure values obtained by ABPM in daytime $(\mathrm{p}<0.001 ; \mathrm{r}=0.539)$, night-time $(\mathrm{p}<0.001 ; \mathrm{r}=0.386)$ and $24 \mathrm{~h}$ period $(\mathrm{p}<0.001$; $r=0.561$ ). Identical results were observed between mean diastolic blood pressure at the office and in

Table 1. Characteristics of lean and obese women (mean \pm SD)

\begin{tabular}{|l|c|c|c|}
\hline & Lean women & Obese women & p value \\
\hline $\mathrm{N}$ & 88 & 107 & 0.561 \\
\hline Age $($ years) & $33.8 \pm 8.4$ & $34.5 \pm 8.3$ & $<0.001$ \\
\hline BMl $\left[\mathrm{kg} / \mathrm{m}^{2}\right]$ & $21.5 \pm 1.7$ & $43.5 \pm 7.5$ & $<0.001$ \\
\hline Total body weight $[\mathrm{kg}]$ & $56.0 \pm 5.3$ & $111.2 \pm 20.8$ & $<0.001$ \\
\hline Total body fat $[\mathrm{kg}]$ & $14.2 \pm 3.6$ & $53.7 \pm 14.5$ & $<0.001$ \\
\hline Percentage of body fat $(\%)$ & $25.0 \pm 4.7$ & $47.7 \pm 5.1$ & $<0.001$ \\
\hline Waist circumference $[\mathrm{cm}]$ & $71.9 \pm 6.0$ & $117.3 \pm 14.3$ & $<0.001$ \\
\hline Hip circumference $[\mathrm{cm}]$ & $97.6 \pm 4.6$ & $134.0 \pm 12.6$ & $<0.001$ \\
\hline Waist-to-hip ratio & $0.74 \pm 0.05$ & $0.88 \pm 0.08$ & $<0.001$ \\
\hline Office systolic BP $[\mathrm{mm} \mathrm{Hg]}$ & $108.6 \pm 12.1$ & $124.7 \pm 16.3$ & $<0.001$ \\
\hline Office diastolic BP $[\mathrm{mm} \mathrm{Hg}]$ & $69.3 \pm 9.7$ & $79.5 \pm 10.3$ & $<$ \\
\hline
\end{tabular}


Table 1. Characteristics of lean and obese women (mean \pm SD)

\begin{tabular}{|c|c|c|c|}
\hline & Lean women & Obese women & $\mathrm{p}$ value \\
\hline ABPM systolic BP in 24h [mm Hg] & $115.9 \pm 9.6$ & $121.0 \pm 9.1$ & $<0.001$ \\
\hline ABPM diastolic BP in 24h [mm Hg] & $72.5 \pm 7.2$ & $72.6 \pm 6.7$ & 0.889 \\
\hline ABPM systolic BP in daytime [mm Hg] & $119.2 \pm 9.6$ & $124.0 \pm 9.7$ & 0.001 \\
\hline ABPM diastolic BP in daytime [mm Hg] & $75.9 \pm 7.2$ & $75.9 \pm 7.5$ & 0.973 \\
\hline ABPM systolic BP in night-time $[\mathrm{mm} \mathrm{Hg}]$ & $106.6 \pm 10.6$ & $112.4 \pm 11.0$ & $<0.001$ \\
\hline ABPM diastolic BP in night-time [mm Hg] & $62.7 \pm 7.6$ & $63.6 \pm 8.2$ & 0.447 \\
\hline Fasting glucose $[\mathrm{mg} / \mathrm{dL}]$ & $81.0 \pm 7.2$ & $93.3 \pm 29.2$ & $<0.001$ \\
\hline Fasting insulin $[\mu \mathrm{Ul} / \mathrm{mL}]$ & $5.9 \pm 3.8$ & $17.7 \pm 11.4$ & $<0.001$ \\
\hline Triglycerides [mg/dL] & $79.8 \pm 29.7$ & $120.6 \pm 78.3$ & $<0.001$ \\
\hline Interleukin-6 [pg/mL] & $1.39 \pm 1.33$ & $2.38 \pm 1.66$ & $<0.001$ \\
\hline TNF- $\alpha[p g / m L]$ & $1.31 \pm 0.81$ & $1.38 \pm 0.89$ & 0.579 \\
\hline High-sensitivity $\mathrm{C}$ reactive protein $[\mathrm{mg} / \mathrm{dL}]$ & $0.22 \pm 0.31$ & $0.96 \pm 0.76$ & $<0.001$ \\
\hline RBP-4 [ng/mL] & $41.3 \pm 12.5$ & $34.2 \pm 16.4$ & 0.001 \\
\hline Leptin [ng/mL] & $10.5 \pm 5.8$ & $36.8 \pm 14.9$ & $<0.001$ \\
\hline Adiponectin $[\mu \mathrm{g} / \mathrm{mL}]$ & $12.3 \pm 5.1$ & $6.9 \pm 3.3$ & $<0.001$ \\
\hline Resistin [ng/mL] & $19.2 \pm 10.7$ & $19.2 \pm 9.6$ & 0.99 \\
\hline MCP-1 [pg/mL] & $324.7 \pm 102.2$ & $374.5 \pm 129.6$ & 0.003 \\
\hline ICAM-1 [ng/mL] & $228.1 \pm 54.2$ & $245.8 \pm 72.8$ & 0.061 \\
\hline VCAM-1 [ng/mL] & $506.7 \pm 182.6$ & $496.9 \pm 186.1$ & 0.714 \\
\hline HOMA-IR & $1.18 \pm 0.76$ & $4.31 \pm 3.56$ & $<0.001$ \\
\hline QUICKI & $0.17 \pm 0.02$ & $0.14 \pm 0.01$ & $<0.001$ \\
\hline McAuley index & $9.50 \pm 1.96$ & $6.4 \pm 1.7$ & $<0.001$ \\
\hline Matsuda formula & ND & $3.92 \pm 2.79$ & - \\
\hline Women on oral contraceptives (\%) & $50.0(44 / 88)$ & $46.7(50 / 107)$ & 0.649 \\
\hline Current smokers (\%) & $35.2(31 / 88)$ & $12.1(13 / 107)$ & $<0.001$ \\
\hline Diagnosed hypertension in first degree relatives $(\%)$ & $55.7(44 / 79)^{*}$ & $54.1(46 / 85)^{*}$ & 0.839 \\
\hline
\end{tabular}

ND — not determined; BMI — body mass index; ABPM — ambulatory blood pressure monitoring; TNF- $\alpha$ — tumor necrosis factor alpha; hs-CRP — high-sensitivity C reactive protein RBP-4 — retinol-binding protein 4; MCP-1 - monocyte chemoattractant protein 1; ICAM-1 — intercellular adhesion molecule 1; VCAM-1 — vascular-cellular adhesion molecule 1; HOMA-IR — homeostasis model assessment of insulin resistance; QUICKI - quantitative insulin sensitivity check index

*Data concerning to the presence/absence of diagnosed hypertension in first degree relatives could not be obtained in 9 lean and in 22 obese women

ABPM in daytime $(\mathrm{p}<0.001 ; \mathrm{r}=0.717)$, night-time $(\mathrm{p}=0.002 ; \mathrm{r}=0.295)$ and $24 \mathrm{~h}$ period $(\mathrm{p}<0.001$ $r=0.43)$. Also in obese women, there was a significant inverse association of age with insulin resistance determined by HOMA-IR ( $\mathrm{p}=0.042 ; \mathrm{r}=-0.197$ ) and a trend for the inverse correlation with BMI $(\mathrm{p}=0.056 ; \mathrm{r}=-0.186)$; age was directly associated with all insulin sensitivity indexes: QUICKI $(\mathrm{p}=0.009 ; \mathrm{r}=0.253)$, McAuley index $(\mathrm{p}=0.007$; $\mathrm{r}=0.261)$, and Matsuda formula $(\mathrm{p}=0.01$; $\mathrm{r}=0.248$ ).

Less strong correlations were observed in the lean women between office-based systolic blood pressure and systolic blood pressure by ABPM in daytime $(\mathrm{p}=0.001 ; \mathrm{r}=0.359)$, night-time $(\mathrm{p}=0.015$; $\mathrm{r}=0.26)$ and $24 \mathrm{~h}$ period $(\mathrm{p}=0.002 ; \mathrm{r}=0.327)$. The same was observed concerning association of diastolic office-based blood pressure and diastolic ABPM mean values in daytime $(\mathrm{p}=0.009 ; \mathrm{r}=0.278)$, night-time $(\mathrm{p}=0.013 ; \mathrm{r}=0.264)$ and $24 \mathrm{~h}(\mathrm{p}=0.015$; $\mathrm{r}=0.258$ ).

For both groups of women, the association between office-based blood pressure and $24 \mathrm{~h}$ values in ABPM for systolic and diastolic blood pressure is exposed graphically in Figures 1 and 2, respectively.

Hypertension based on office measurements of blood pressure was more prevalent among obese women (Tab. 2), but that difference was not observed on ambulatory blood pressure monitoring (Tab. 3). Likewise, no difference between obese and lean groups was observed if we considered ABPM criteria for hypertension in daytime (16.8\% vs. $15.9 \%)$, night-time 


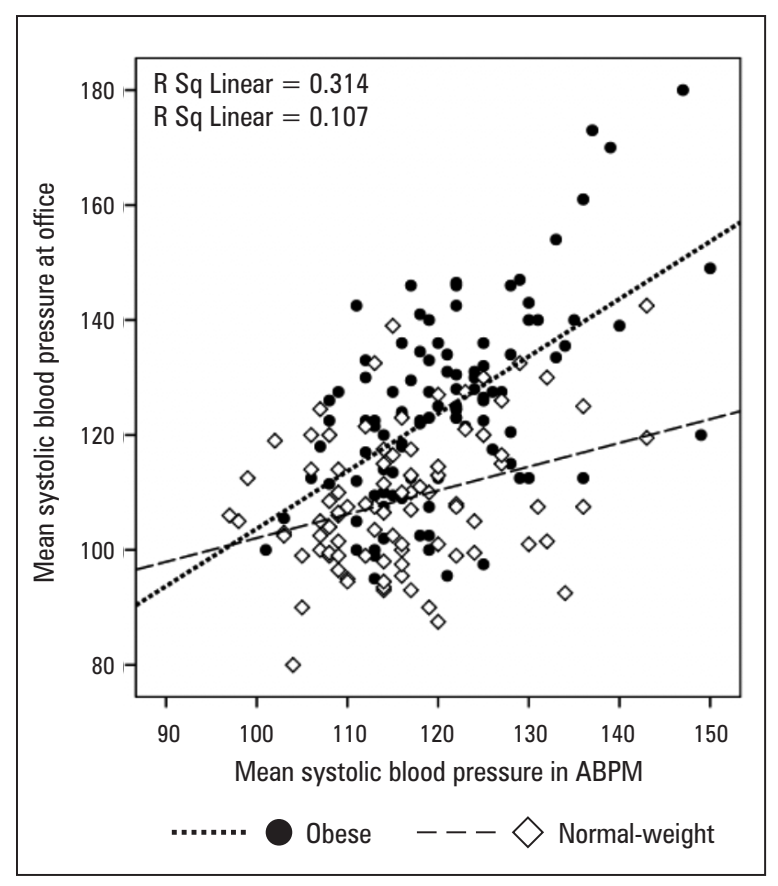

Figure 1. Correlation of mean systolic office-based blood pressure and mean values in $24 \mathrm{~h}$ ambulatory blood pressure monitoring, in obese and normal-weight women

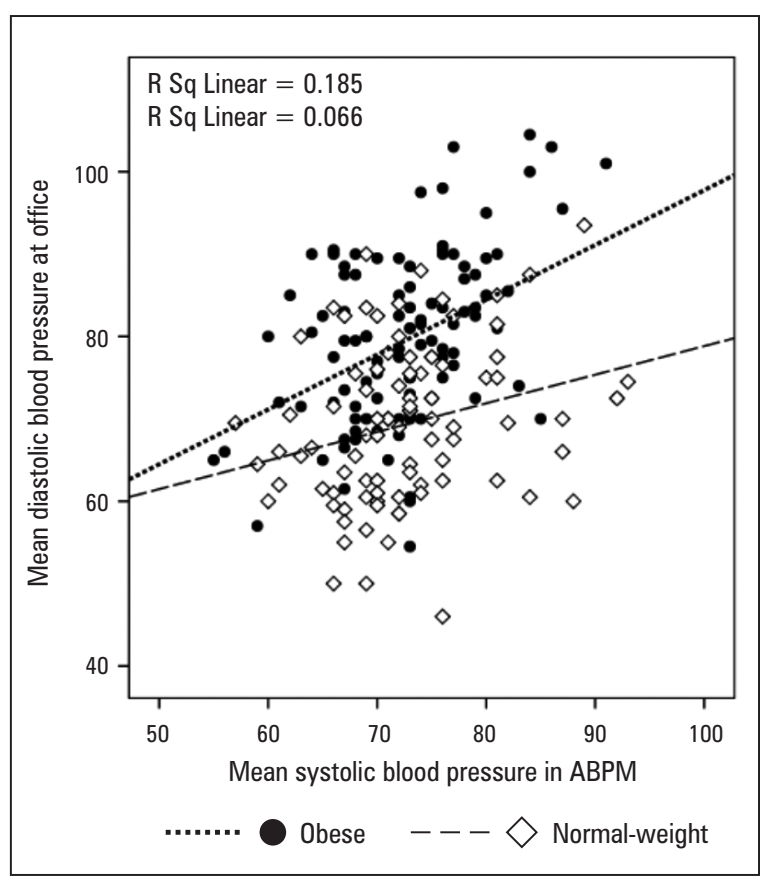

Figure 2. Correlation of mean diastolic office-based blood pressure and mean values in $24 \mathrm{~h}$ ambulatory blood pressure monitoring, in obese and normal-weight women

Table 2. Obese and lean women meeting criteria for hypertension by office-based blood pressure

\begin{tabular}{|c|c|c|c|c|}
\hline \multirow{2}{*}{\multicolumn{2}{|c|}{$\mathrm{p}<0.001$}} & \multicolumn{2}{|c|}{ Office-based blood pressure criteria for hypertension } & \multirow{3}{*}{$\begin{array}{c}\text { Total } \\
107 \\
(100 \%)\end{array}$} \\
\hline & & Yes & No & \\
\hline \multirow{2}{*}{ Group } & Obese women & $\begin{array}{c}28 \\
(26.2 \%)\end{array}$ & $\begin{array}{c}79 \\
(73.8 \%)\end{array}$ & \\
\hline & Lean women & $\begin{array}{c}3 \\
(3.4 \%)\end{array}$ & $\begin{array}{c}85 \\
(96.6 \%)\end{array}$ & $\begin{array}{c}88 \\
(100 \%)\end{array}$ \\
\hline & Total & $\begin{array}{c}31 \\
(15.9 \%)\end{array}$ & $\begin{array}{c}164 \\
(84.1 \%)\end{array}$ & $\begin{array}{c}195 \\
(100 \%)\end{array}$ \\
\hline
\end{tabular}

Table 3. Obese and lean women meeting criteria for hypertension by ambulatory blood pressure monitoring

\begin{tabular}{|c|c|c|c|c|}
\hline \multirow{2}{*}{\multicolumn{2}{|c|}{$p=0.199$}} & \multicolumn{2}{|c|}{$\begin{array}{c}\text { Ambulatory blood pressure monitoring criteria } \\
\text { for hypertension }\end{array}$} & \multirow{3}{*}{$\begin{array}{c}\text { Total } \\
107 \\
(100 \%)\end{array}$} \\
\hline & & Yes & No & \\
\hline \multirow{2}{*}{ Group } & Obese women & $\begin{array}{c}41 \\
(38.3 \%)\end{array}$ & $\begin{array}{c}66 \\
(61.7 \%)\end{array}$ & \\
\hline & Lean women & $\begin{array}{c}26 \\
(29.5 \%)\end{array}$ & $\begin{array}{c}62 \\
(70.5 \%)\end{array}$ & $\begin{array}{c}88 \\
(100 \%)\end{array}$ \\
\hline & Total & $\begin{array}{c}67 \\
(34.4 \%)\end{array}$ & $\begin{array}{c}128 \\
(65.6 \%)\end{array}$ & $\begin{array}{c}195 \\
(100 \%)\end{array}$ \\
\hline
\end{tabular}

(31.1\% vs. $27.6 \%)$ and $24 \mathrm{~h}(19.6 \%$ vs. $18.2 \%)$ periods separately. When comparing those diagnosed for hypertension by office-based measurements with those based on ABPM, different populations were found (Tab. 4). That was also true if we compared office-based hypertensive women with those with daytime $(\mathrm{p}<0.001)$, night-time $(\mathrm{p}=0.012)$ and $24 \mathrm{~h}$ $(\mathrm{p}<0.001)$ criteria for hypertension.

Non-dipper pattern of blood pressure variation was more prevalent in obese than in lean women 
Table 4. Comparison of hypertensive groups by office-based and ambulatory blood pressure monitoring considering only obese women and both groups together

\begin{tabular}{|c|c|c|c|c|}
\hline & & \multicolumn{2}{|c|}{$\begin{array}{l}\text { Ambulatory blood pressure monitoring criteria } \\
\text { for hypertension }\end{array}$} & \multirow[t]{2}{*}{ Total } \\
\hline & & Yes & No & \\
\hline \multicolumn{5}{|c|}{ Obese women $(p=0.005)$} \\
\hline \multirow{3}{*}{$\begin{array}{l}\text { Office-based blood } \\
\text { pressure criteria } \\
\text { for hypertension }\end{array}$} & Yes & $\begin{array}{c}17 \\
(15.9 \%)\end{array}$ & $\begin{array}{c}11 \\
(10.3 \%)\end{array}$ & $\begin{array}{c}28 \\
(26.2 \%) \\
\end{array}$ \\
\hline & No & $\begin{array}{c}24 \\
(22.4 \%)\end{array}$ & $\begin{array}{c}55 \\
(51.4 \%)\end{array}$ & $\begin{array}{c}79 \\
(73.8 \%)\end{array}$ \\
\hline & Total & $\begin{array}{c}41 \\
(38.3 \%)\end{array}$ & $\begin{array}{c}66 \\
(61.7 \%)\end{array}$ & $\begin{array}{c}107 \\
(100 \%)\end{array}$ \\
\hline \multicolumn{5}{|c|}{ Both groups together $(p=0.001)$} \\
\hline \multirow{3}{*}{$\begin{array}{l}\text { Office-based blood } \\
\text { pressure criteria } \\
\text { for hypertension }\end{array}$} & Yes & $\begin{array}{c}19 \\
(9.8 \%) \\
\end{array}$ & $\begin{array}{c}12 \\
(6.1 \%) \\
\end{array}$ & $\begin{array}{c}31 \\
(15.9 \%) \\
\end{array}$ \\
\hline & No & $\begin{array}{c}48 \\
(24.6 \%)\end{array}$ & $\begin{array}{c}116 \\
(59.5 \%)\end{array}$ & $\begin{array}{c}164 \\
(84.1 \%)\end{array}$ \\
\hline & Total & $\begin{array}{c}67 \\
(34.4 \%)\end{array}$ & $\begin{array}{c}128 \\
(65.6 \%)\end{array}$ & $\begin{array}{c}195 \\
(100 \%)\end{array}$ \\
\hline
\end{tabular}

(39.6\% vs. $24.1 \% ; \mathrm{p}=0.022)$. Considering each group of women, the prevalence of non-dippers was lower in those who fitted the criteria for night-time hypertension than in those who did not, either in obese $(\mathrm{p}=0.001)$ or in lean women $(\mathrm{p}=0.018)$.

In obese women several direct correlations exist between blood pressure, insulin resistance and some markers of subclinical inflammation or atherogenesis. Moreover, some particular inverse correlations were present between some of those parameters and the degree of nocturnal fall in blood pressure. By a stepwise multiple regression analysis HOMA-IR and body fat percentage were found to be independently associated to $24 \mathrm{~h}\left(\mathrm{r}^{2}=0.176\right)$ and daytime $\left(r^{2}=0.111\right)$ systolic blood pressure; HOMA-IR and waist circumference were independently associated with night-time systolic blood pressure $\left(\mathrm{r}^{2}=0.202\right)$. Fasting glucose was associated with daytime $(\mathrm{p}=0.039 ; \mathrm{r}=0.199)$ and $24 \mathrm{~h}$ diastolic blood pressure $(p=0.008 ; r=0.256)$. Night-time diastolic blood pressure was correlated with HOMA-IR $(\mathrm{p}=0.003 ; \mathrm{r}=0.286)$ and QUICKI $(\mathrm{p}=0.017$; $\mathrm{r}=-0.231)$. By a stepwise multiple regression analysis, it was shown that TNF- $\alpha$ levels (inversely), age and QUICKI (directly) were all independently correlated with the dipping phenomenon $\left(r^{2}=0.172\right)$. Adiponectin circulating levels (inversely), age, BMI, and fasting glucose (directly) were all independently correlated to systolic $\left(\mathrm{r}^{2}=0.226\right)$ and diastolic $\left(r^{2}=0.215\right)$ office-based blood pressure.

By contrast, among lean women an independent association exists between MCP-1 circulating levels and diastolic blood pressure in daytime $(\mathrm{p}=0.013$; $r=0.269)$ and $24 \mathrm{~h}$ period $(\mathrm{p}=0.013 ; \mathrm{r}=0.267)$ ABPM. Systolic office-based blood pressure was associated with waist-to-hip ratio $(\mathrm{p}=0.01 ; \mathrm{r}=0.273)$; waist-to-hip ratio and RBP-4 circulating levels were independently associated with diastolic office-based blood pressure $\left(r^{2}=0.12\right)$. In this group of women, no association was found for the dipping phenomenon with any of the parameters considered in this study.

\section{Discussion}

As classically described, obesity is associated with high blood pressure $[1,2]$. That was also shown in this study for office-based systolic and diastolic blood pressure and for systolic blood pressure in all periods considered in ABPM. Although a high correlation was present between office-based and ABPM, it was found a significant difference in hypertension prevalence between obese and lean women for office-based criteria but not for ABPM criteria. In concordance to these data, we confirmed that the group of women diagnosed with hypertension by one criterion does not fit in the hypertension definition by the other. For the definition of daytime and night-time we considered fixed schedules. One possibility for the dissimilarity between criteria could be the fact that some women had daytime-like activities over 11:00 pm or before 07:00 am. If it would be the case, mean night-time blood pressure values would be expected to increase 
leading to a higher prevalence of night-time hypertension and exaggerating hypertension rates based in ABPM [15]. Nevertheless, that explanation does not appear to fit; if we compared women with office-based hypertension with those with hypertension criteria based on daytime, the difference was even greater $(p<0.001)$ than if we compared with those with night-time hypertension $(\mathrm{p}=0.012)$.

All the factors that were independently associated with office-based blood pressure values in obese women (i.e. age, BMI, fasting glucose, and adiponectin), and that explains more than one fifth of its variation, are in line with previous reports in the literature [5, 16-18]. Also based on ABPM, it was shown a direct association of systolic blood pressure with anthropometrics. The net association between fasting glucose levels and diastolic blood pressure is concordant with the close relationship that exists between hypertension and glucose intolerance states. Hypertension is more prevalent in individuals with type 2 diabetes and intermediate hyperglycemia and these conditions are more prevalent among individuals diagnosed with hypertension [17-19]. Independently from anthropometrics, insulin resistance was also directly associated with blood pressure values in obese women. This is in line with the evidence of insulin resistance per se as a contributing factor for hypertension. There are several mechanistic explanations for the association between insulin resistance and blood pressure increase; one of those mechanisms involves sympathetic activation. [20]. The greater sympathetic activity in insulin resistant women would explain the higher night-time blood pressure values and the non-dipping pattern observed. Non-dippers have also been reported to be more prevalent in conditions characterized by insulin resistance [21].

The inverse independent association of TNF- $\alpha$ with the dipping status would be expected in the context of a higher atherogenic-related subclinical inflammation state [22]. Assuming non-dipper status as a cardiovascular risk factor it would be logical to find higher levels of several atherogenic markers, but it was not the case. Another possible explanation for the inverse association of TNF- $\alpha$ with dipping phenomenon could be through induction of insulin resistance [23]. Nevertheless, that association is independent of insulin sensitivity and no association could be found between TNF- $\alpha$ and insulin resistance indexes in this study. On the other hand, TNF- $\alpha$ itself could have some direct effect on vasculature inducing endothelial dysfunction and a decrease in nitric oxide synthesis as previously demonstrated in rats $[24,25]$.

Aging is characterized by an increase in sympathetic activity [26]. However, in this study it was found an inverse association between age and dipping in obese women. It is true that there was a trend for the inverse correlation of age with BMI and that age was directly associated with insulin sensitivity. Nevertheless, the association of age with the dipping status was independent of those two parameters. For the inclusion criteria only women without any known health condition (other than obesity) were accepted. The age ranged from 18 to 50 years old but it was especially difficult to find obese women above the age of 35 (and a more prolonged history of obesity) with no known comorbidities. Perhaps those older obese women selected belong to the so-called relatively benign obesity or metabolically healthy but obese individuals, i.e. those with obesity but without the metabolic and cardiovascular risks as expected for the degree of excessive body fat $[27,28]$.

Opposite to the obese group, in lean women all the above associations were missing. That could be the case because most of the parameters shown to be associated with blood pressure parameters in the obese group were lower in lean women. Thus there was still no deleterious involvement on blood pressure control. One exception was anthropometry, confirming that it exerts an effect on blood pressure even in the absence of excessive body fat mass.

Although an association exists between mean blood pressure levels in ABPM and those obtained by standard measurement in the office setting, whether we use one or the other for the diagnosis of hypertension we are identifying different groups of women. In obese women, anthropometrics and insulin resistance are main determinants of blood pressure in ABPM. Age, anthropometrics, fasting glucose, and adiponectin circulating levels all influence office-based blood pressure levels, explaining a little more than $20 \%$ of it. On the other hand, age, insulin resistance and TNF- $\alpha$ levels are all independent determinants of blood pressure fall during night-time. Even though assuming a lower cardiovascular risk compared to the classic obesity, metabolically healthy but obese women present higher blood pressure (essentially systolic blood pressure). However, no strong correlation exists between blood pressure or the dipping phenomenon and subclinical inflammation or markers of atherosclerosis activity either in lean or in metabolically healthy but obese women.

\section{Declaration of interest}

The authors declare no conflict of interest in the area.

\section{Funding}

This work was funded by a Merck S.A. grant for investigation in obesity. 


\section{References}

1. Kotchen TA. Obesity-related hypertension: epidemiology, pathophysiology, and clinical management. Am J Hypertens. 2010; 23(11): 1170-1178, doi: 10.1038/ajh.2010.172, indexed in Pubmed: 20706196.

2. Nguyen NT, Magno CP, Lane KT, et al. Association of hypertension, diabetes, dyslipidemia, and metabolic syndrome with obesity: findings from the National Health and Nutrition Examination Survey, 1999 to 2004. J Am Coll Surg. 2008; 207(6): 928-934, doi: 10.1016/j. jamcollsurg.2008.08.022, indexed in Pubmed: 19183541.

3. Narkiewicz K. Diagnosis and management of hypertension in obesity. Obes Rev. 2006; 7(2): 155-162, doi: 10.1111/j.1467789X.2006.00226.x, indexed in Pubmed: 16629872.

4. Zhou J, Qin G. Adipocyte dysfunction and hypertension. Am J Cardiovasc Dis. 2012; 2(2): 143-149, indexed in Pubmed: 22720204.

5. Dorresteijn JAN, Visseren FLJ, Spiering W. Mechanisms linking obesity to hypertension. Obes Rev. 2012; 13(1): 1726, doi: 10.1111/j.1467-789X.2011.00914.x, indexed in Pubmed: 21831233.

6. Hajer GR, van Haeften TW, Visseren FLJ. Adipose tissue dysfunction in obesity, diabetes, and vascular diseases. Eur Heart J. 2008; 29(24): 2959-2971, doi: 10.1093/eurheartj/ehn387, indexed in Pubmed: 18775919.

7. Seravalle G, Grassi G. Obesity and hypertension. Pharmaco Res. 2017; 122: 1-7, doi: 10.1016/j.phrs.2017.05.013, indexed in Pubmed: 28532816.

8. Wang ZV, Scherer PE. Adiponectin, cardiovascular function, and hypertension. Hypertension. 2008; 51(1): 8-14, doi: 10.1161/HYPERTENSIONAHA.107.099424, indexed in Pubmed: 17998473.

9. Orlando A, Nava E, Giussani M, et al. Adiponectin and Cardiovascular Risk. From Pathophysiology to Clinic: Focus on Children and Adolescents. Int J Mol Sci. 2019; 20(13), doi: 10.3390/ ijms20133228, indexed in Pubmed: 31262082.

10. Li FYL, Cheng KKY, Lam KSL, et al. Cross-talk between adipose tissue and vasculature: role of adiponectin. Acta Physiol (Oxf). 2011; 203(1): 167-180, doi: 10.1111/j.1748-1716.2010.02216.x, indexed in Pubmed: 21062420.

11. Kalil GZ, Haynes WG. Sympathetic nervous system in obesityrelated hypertension: mechanisms and clinical implications. Hypertens Res. 2012; 35(1): 4-16, doi: 10.1038/hr.2011.173, indexed in Pubmed: 22048570.

12. Lambert EA, Esler MD, Schlaich MP, et al. Obesity-Associated Organ Damage and Sympathetic Nervous Activity. Hypertension. 2019; 73(6): 1150-1159, doi: 10.1161/HYPERTENSIONAHA.118.11676, indexed in Pubmed: 31067200.

13. Dauphinot V, Gosse P, Kossovsky MP, et al. Autonomic nervous system activity is independently associated with the risk of shift in the non-dipper blood pressure pattern. Hypertens Res. 2010; 33(10): 1032-1037, doi: $10.1038 / \mathrm{hr} .2010 .130$, indexed in Pubmed: 20668452.

14. Mancia G, De Ba, Dominiczak A, et al. 2007 Guidelines for the Management of Arterial Hypertension: The Task Force for the Management of Arterial Hypertension of the European Society of Hypertension (ESH) and of the European Society of Cardiol- ogy (ESC). J Hypertens. 2007; 25(6): 1105-1187, doi: $10.1097 /$ HJH.0b013e3281fc975a, indexed in Pubmed: 17563527.

15. Japanese Circulation Society Joint Working Group. Guidelines for the clinical use of 24 hour ambulatory blood pressure monitoring (ABPM) (JCS 2010). Circ J. 2012; 76(2): 508-19, doi: 10.1253/ circj.cj-88-0020, indexed in Pubmed: 22230784

16. Franklin SS, Gustin W, Wong ND, et al. Hemodynamic patterns of age-related changes in blood pressure. The Framingham Heart Study. Circulation. 1997; 96(1):308-315, doi: 10.1161/01.cir.96.1.308, indexed in Pubmed: 9236450.

17. Sowers JR, Epstein M, Frohlich ED, et al. Diabetes mellitus and associated hypertension, vascular disease, and nephropathy. An update. Hypertension. 1995; 26(6 Pt 1): 869-879, doi: 10.1161/01. hyp.26.6.869, indexed in Pubmed: 7490142.

18. Gress TW, Nieto FJ, Shahar E, et al. Hypertension and antihypertensive therapy as risk factors for type 2 diabetes mellitus. Atherosclerosis Risk in Communities Study. N Engl J Med. 2000; 342(13): 905-912, doi: 10.1056/NEJM200003303421301, indexed in Pubmed: 10738048.

19. Schmieder RE, Tschöpe D, Koch C, et al. DIALOGUE study group.. Individualised treatment targets in patients with type- 2 diabetes and hypertension. Cardiovasc Diabetol. 2018; 17(1): 18, doi: 10.1186/ s12933-018-0661-8, indexed in Pubmed: 29357854.

20. Kurukulasuriya LR, Stas S, Lastra G, et al. Hypertension in obesity. Med Clin North Am. 2011; 95(5): 903-917, doi: 10.1016/j. mcna.2011.06.004, indexed in Pubmed: 21855699.

21. Kotsis V, Stabouli S, Bouldin M, et al. Impact of obesity on 24-hour ambulatory blood pressure and hypertension. Hypertension. 2005; 45(4): 602-607, doi: 10.1161/01.HYP.0000158261.86674.8e, indexed in Pubmed: 15723966.

22. Fantuzzi G, Mazzone T. Adipose tissue and atherosclerosis: exploring the connection. Arterioscler Thromb Vasc Biol. 2007; 27(5): 996-1003, doi: 10.1161/ATVBAHA.106.131755, indexed in Pubmed: 17303782.

23. Antuna-Puente B, Feve B, Fellahi S, et al. Adipokines: the missing link between insulin resistance and obesity. Diabetes Metab. 2008; 34(1): 2-11, doi: 10.1016/j.diabet.2007.09.004, indexed in Pubmed: 18093861.

24. Ramseyer VD, Hong NJ, Garvin JL. Tumor necrosis factor $\alpha$ decreases nitric oxide synthase type 3 expression primarily via Rho/ Rho kinase in the thick ascending limb. Hypertension. 2012; 59(6): 1145-1150, doi: 10.1161/HYPERTENSIONAHA.111.189761, indexed in Pubmed: 22566503.

25. Engin A. Endothelial Dysfunction in Obesity. Adv Exp Med Biol. 2017; 960: 345-379, doi: 10.1007/978-3-319-48382-5_15, indexed in Pubmed: 28585207.

26. Hering D, Somers VK, Kara T, et al. Sympathetic neural responses to smoking are age dependent. J Hypertens. 2006; 24(4): 691-695, doi: 10.1097/01.hjh.0000217851.95583.57, indexed in Pubmed: 16531797.

27. Primeau V, Coderre L, Karelis AD, et al. Characterizing the profile of obese patients who are metabolically healthy. Int J Obes (Lond). 2011; 35(7): 971-981, doi: 10.1038/ijo.2010.216, indexed in Pubmed: 20975726.

28. Beh $S$. Is metabolically healthy obesity a useful concept? Diabet Med. 2019; 36(5): 539-545, doi: 10.1111/dme.13869, indexed in Pubmed: 30474298. 